\title{
Recent Trends on Liquid Air Energy Storage: A Bibliometric Analysis
}

\author{
Emiliano Borri ${ }^{1}\left(\mathbb{D}\right.$, Alessio Tafone ${ }^{2}(0)$, Gabriel Zsembinszki ${ }^{1}$, Gabriele Comodi ${ }^{3}(\mathbb{C}$, \\ Alessandro Romagnoli ${ }^{4}$ and Luisa F. Cabeza ${ }^{1, *(D)}$ \\ 1 GREiA Research Group, Universitat de Lleida, Pere de Cabrera s/n, 25001 Lleida, Spain; \\ emiliano.borri@udl.cat (E.B.); gabriel.zsembinszki@udl.cat (G.Z.) \\ 2 Energy Research Institute @ NTU, 1 Cleantech Loop, Singapore 637141, Singapore; \\ ALESSIO001@e.ntu.edu.sg \\ 3 Dipartimento di Ingegneria Industriale e Scienze Matematiche-Università Politecnica delle Marche, \\ 60131 Ancona, Italy; g.comodi@univpm.it \\ 4 School of Mechanical and Aerospace Engineering, Nanyang Technological University, 50 Nanyang Avenue, \\ Singapore 639798, Singapore; A.Romagnoli@ntu.edu.sg \\ * Correspondence: luisaf.cabeza@udl.cat; Tel.: +34-973-003-576
}

Received: 6 March 2020; Accepted: 13 April 2020; Published: 16 April 2020

\begin{abstract}
The increasing penetration of renewable energy has led electrical energy storage systems to have a key role in balancing and increasing the efficiency of the grid. Liquid air energy storage (LAES) is a promising technology, mainly proposed for large scale applications, which uses cryogen (liquid air) as energy vector. Compared to other similar large-scale technologies such as compressed air energy storage or pumped hydroelectric energy storage, the use of liquid air as a storage medium allows a high energy density to be reached and overcomes the problem related to geological constraints. Furthermore, when integrated with high-grade waste cold/waste heat resources such as the liquefied natural gas regasification process and hot combustion gases discharged to the atmosphere, LAES has the capacity to significantly increase the round-trip efficiency. Although the first document in the literature on the topic of LAES appeared in 1974, this technology has gained the attention of many researchers around the world only in recent years, leading to a rapid increase in a scientific production and the realization of two system prototype located in the United Kingdom (UK). This study aims to report the current status of the scientific progress through a bibliometric analysis, defining the hotspots and research trends of LAES technology. The results can be used by researchers and manufacturers involved in this entering technology to understand the state of art, the trend of scientific production, the current networks of worldwide institutions, and the authors connected through the LAES. Our conclusions report useful advice for the future research, highlighting the research trend and the current gaps.
\end{abstract}

Keywords: liquid air energy storage; LAES; literature review; bibliometric analysis

\section{Introduction}

Energy in whatever form is an essential source that guarantees a high-quality standard of life in modern society. Due to the concomitant effect of population growth and the rapid development of emerging countries, energy demand is dramatically increasing year by year. 2018 witnessed a remarkable trend for energy demand, increasing at almost twice the average rate for the decade since 2010, with a remarkable fossil fuel share of $81 \%$ [1]. Unfortunately, fossil fuel combustion has long been recognized as the main cause for some serious environmental issues including the greenhouse effect, ozone layer depletion and acid rain [2] as well as social costs linked with combustion emissions [3]. 
Moreover, despite the commitment of many countries to reach an early peak in emissions related to fossil fuel consumption, in 2018, the energy-related carbon dioxide $\left(\mathrm{CO}_{2}\right)$ emissions reached the highest annual increase since $2013(+1.9 \%)$ [1].

Nowadays, a key role in solving the environmental challenges posed by traditional fossil fuel depletion is being played by renewable energy sources (RESs), namely energy from sources that are naturally replenishing, but limited in the amount of energy that is available per unit of time. As a consequence, the use of renewable energy systems, namely technologies harnessing the energy from RESs, increased significantly during the early 2000s due to the mix of supporting policies and rapidly falling costs ( $-70 \%$ for solar PV and $-25 \%$ for wind), and according to the Stated Policies Scenario [1], in 2018, the share of renewables in global electricity generation achieved nearly $26 \%$, with a 2040 projection up to $44 \%$. The rapid development and penetration of renewable energy sources in electricity grids influence the whole system's reliability and stability. Unlike most conventional power plants, renewable power ones are generally smaller in size and are not capable of supplying demand at any time due to renewable energy source intermittency. In fact, highly dependent on weather conditions, most of the renewable energy sources (wind and solar primarily) cannot be dispatched: if not stored, they must be utilized as soon as they are generated. As a consequence, their integration into the existing grid and in stand-alone mode represents a serious challenge for grid balance to meet the energy supply and demand through the chain of generation, transmission, distribution, and end-use.

Amongst all the viable solutions to deal with this issue, electrical energy storage (EES) is recognized as one of the most promising technologies. EES technology refers to the process of converting energy from one form (mainly electrical energy) to a storable form and reserving it in various mediums; then the stored energy can be converted back into electrical energy when needed. Indeed, future electricity grids are planned to use large proportions of intermittent energy sources. Therefore, an increasing scale-up of energy storage is necessary to match the supply with the electricity demand profiles. Reflecting this, the International Energy Agency [4] has projected that $310 \mathrm{GW}$ of additional grid-connected electricity storage capacity will be necessary in the United States, Europe, China, and India. EES technologies are available for different applications at different scales [5] with the predominance of batteries, pumped hydroelectricity storage (PHS), and compressed air energy storage (CAES).

Among the large scale EES technologies, liquid air energy storage (LAES) has attracted significant attention in recent years due to several advantages. Indeed, LAES is a promising and novel long term cryogenic energy storage technology, suitable from mid to large scale applications. Compared to other energy storage systems, LAES guarantees higher volumetric energy density $(214 \mathrm{Wh} / \mathrm{kg})$ and no geographical constrains [6]. The system relies on well-established technologies that limit possible development risks and ensure long life to the system (30-40 years) [7]. Due to its great flexibility under different off-design operations, integration with other thermal processes such as waste heat/cold recovery enables the energy storage efficiency to be increased [8]. One of the most interesting features of the LAES technology is that it can simultaneously produce both electricity and free cooling energy from the electric generator and the liquid air regasification/expansion process, respectively [9]. Metaphorically speaking, LAES is being configured as a technological bridge between the necessities to enhance RES exploitation and the reasons behind the cold economy concept [10]. Indeed, dealing with the compelling necessity to face the booming of cooling demand that may put the reliability of the electricity grid at stake, LAES is playing a crucial role thanks to the potential to, above all, provide free cooling energy during the energy demand peak period [11].

Recalling the battery analogy, the LAES can be separated into three sub-processes: charge, store, and discharge. Figure 1 illustrates a schematic of a stand-alone LAES configuration. During the charge phase, the gaseous air is compressed and turned into liquid air after passing through a throttle valve (J-T valve) and phase separator; the liquid air is then stored in a low pressure cryogenic tank (LA Tank). During the discharge phase, the liquid air is pumped to high pressure by means of a cryogenic pump and regasified; the excess cold released during regasification is stored in a high grade cold storage (HGCS), which serves as a regenerator. Indeed, the cold energy recovered in the HGCS can be used to 
assist the liquefaction process during the charge phase. The high pressure air gas will then be further heated up at the superheaters (SHs) by means of the heat coming from a so called high grade warm storage (HGWS), which stores the heat of the compression released during the charge phase. The high pressure and high temperature gaseous air is then re-heated in a four stage expansion process to achieve a quasi-isothermal expansion.

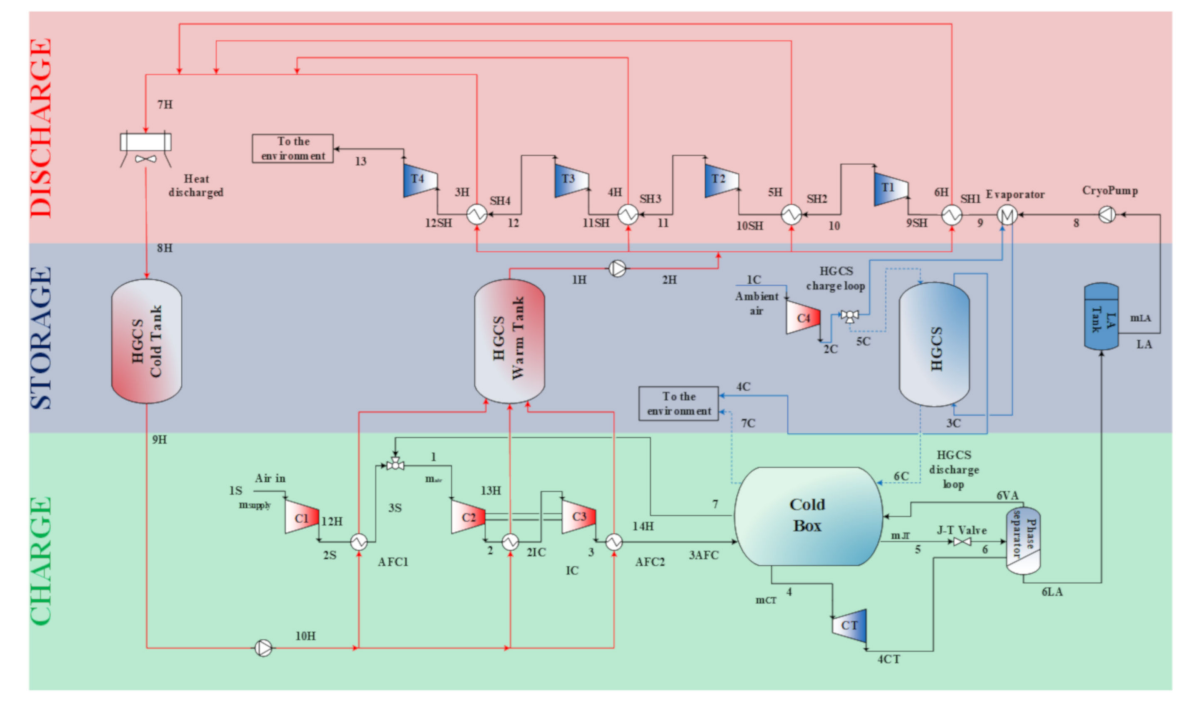

Figure 1. Process flow diagram of liquid air energy storage (LAES). Adapted from [12].

The characteristics and advantages related to the LAES has attracted the attention of many researchers, which has led to a rapid increase in scientific production focused on this technology. However, the potential of LAES has not fully demonstrated yet. This shows the possibilities of new challenges that can bring this technology to the next level. However, advancing in the current technological level is not straightforward, requiring significant investments in this technology and a strong cooperation between both academia and industry. To evaluate the research trend and the future perspectives on LAES, bibliometric analysis techniques represent a statistical method that allows the growth and the scientific progress of a certain topic to be evaluated, giving an overall view of today's research. Furthermore, bibliometric analysis enhances science as a knowledge-generating system [13]. The simplicity and the effectiveness allow for bibliometric analysis to be applied to different scientific areas. Mao et al. [14] analyzed the trend on biomass energy from 1998 to 2013 through a bibliometric technique. The analysis was based on the Science Citation Index (SCI) and the Web of Science database. Results showed how the research in biomass has increased in the past 16 years with an actual strong focus on bioenergy applications. Calderon et al. [15] used bibliometric analysis to study the evolution of the research in the field of thermal energy storage (TES). The study based on the Web of Science core collection database included a survey of different TES system categories. Bartolini et al. [16] integrated a bibliometric analysis into a systematic review of green warehousing to evaluate the current state of research. The study analyzed the most common themes investigated, providing in the conclusions some research recommendations that considered the lack in the topic and a possible interesting study that could be conducted in the field of green warehousing. Du et al. [17] analyzed the literature outputs related to solar energy from 1992 to 2011 through a bibliometric analysis based on social sciences and the citation index. The study identified the main trend in the solar energy research field such as hydrogen production, desalination, drying, heat pumps, biomass, and air conditioning, and provided recommendations for future research that included nanoscience and molecular biology.

Therefore, to define the prospects and the new challenges in storing the energy through the use of liquid air (with the LAES technology), this paper analyzed by means of bibliometric analysis techniques, the trend of the scientific research involved in the study of LAES. The results of the bibliometric analysis proposed in this study can be useful to inspire researchers and manufacturers interested in LAES 
technology in helping to understand the state-of-the-art in the literature, highlighting the hotspots linked to LAES of today and future research.

\section{Methodology}

In the bibliometric analysis studied in this paper, the database Scopus was used as a reference, since it includes a large number of works referring to technological topics compared to other databases such as Web of Science [18]. Furthermore, Google Scholar was not taken into account in the literature search due to the poor accuracy of results, as reported by Falagas et al. [19]. Figure 2 shows a schematic of the methodology followed for the bibliometric analysis. The formulation of the query was based on key terms frequently used in the keywords and abstract contained in the paper related to LAES. It is worth mentioning that although some authors in the literature have often referred to LAES technology using the term cryogenic energy storage (CES) [20], terms such as "cryogenic" were not included in the query since it led to papers related to cryogeny (or low temperature applications), but not related to LAES. The literature search presented in this work was based on the following query: ("liquid air energy storage" OR ("energy storage" AND ("liquid air")) AND NOT ("graphene hydrogel" OR "supercapacitor*" OR "polymer" OR "biosensor*" OR "hot working" OR "laser power system*" OR "LNGES")) with the last access on November 2019. The results were elaborated to obtain the trend and number of works distributed by type of journal, subject, countries, institutions, and authors. An analysis of the keywords was carried out to identify the hot topics and the main thematic related to LAES to help to define the research trend and future prospective. To identify the link between authors, countries, institutions, and keywords, results were graphically elaborated by means of the software VOSviewer [21].

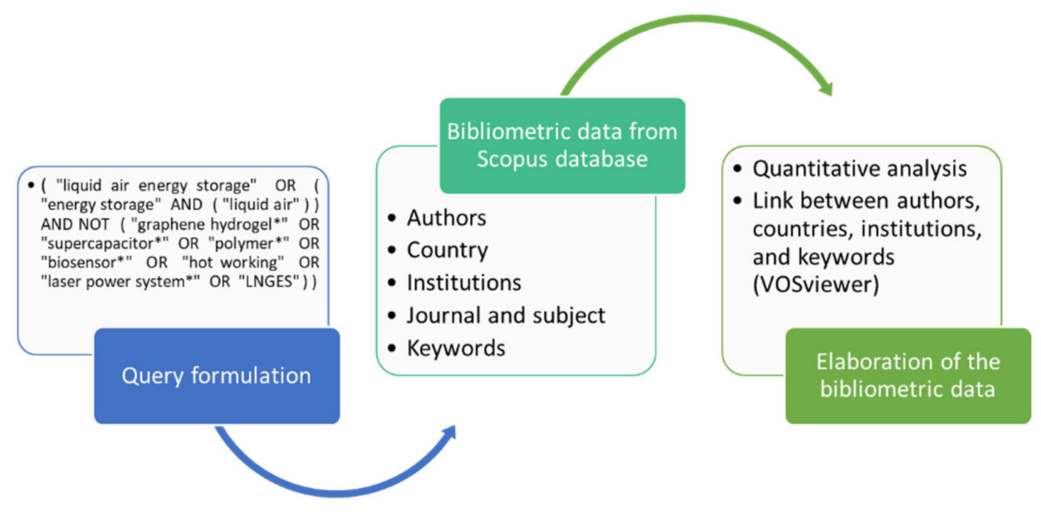

Figure 2. Methodology used for the bibliometric analysis.

\section{Results and Discussion}

This section reports the results of the bibliometric analysis conducted with the methodology described above. The database Scopus, with the query selected, gave a total of 387 documents. An analysis of this first output resulted in the inclusion of papers that were not related to the topic of LAES. Restricting the query research only to title, abstract, and keywords, (TITLE-ABS-KEY ("query")), the database Scopus gave a total number of 132 documents. As mentioned in the methodology, the possibility that some documents were not caught with the query selected was due to the absence of key terms in the keywords and the abstract that mentioned the use of liquid air as energy storage. This highlights the importance of the use of proper terminology in the abstract and a proper selection of keywords. Analyzing the output, the documents given were strictly related to the LAES topic, confirming a correct formulation of the query. The results of the bibliometric analysis shown in this section were obtained elaborating and analyzing the data of all 132 papers collected from the Scopus database. Furthermore, some of the works reported in the reference section were selected and cited 
to support the discussion of results and exemplify the analysis of the keywords used to describe the state-of-art and the hotspots in the topic of LAES.

\subsection{Publications Trend and Distribution by Journal and Subject}

Figure 3 shows the trend of the publications in the Scopus database year by year. From the figure, it is possible to notice that the first publication that included the first concept of LAES appeared in 1974, authored by Sheperd [22], with one more publication in 1977 by Smith [23], and one in 1978 by de Marchi Desenzani [24]. After one additional paper was published in 1982 by Dooley et al. [25], no documents regarding liquid air as energy storage were published until the year 1998 in Japan by Mitsubishi-Hitachi [26-31], with no further developments after 2002. Figure 3 also shows that the trend started again in 2010, reaching a first peak in 2015 (13 publications) and then again in 2017, 2018, and 2019, where the largest number of studies published occurred. The gain in interest in LAES technology can be attributed to the realization of the first LAES pilot plant with a project started in 2008 in the United Kingdom [32]. The first experimental results of the pilot plant, located now at the University of Birmingham, were reported in a work published by Morgan et al. [33] in 2015 that, according to the Scopus database, has the highest number of citations amongst the publications related to LAES.

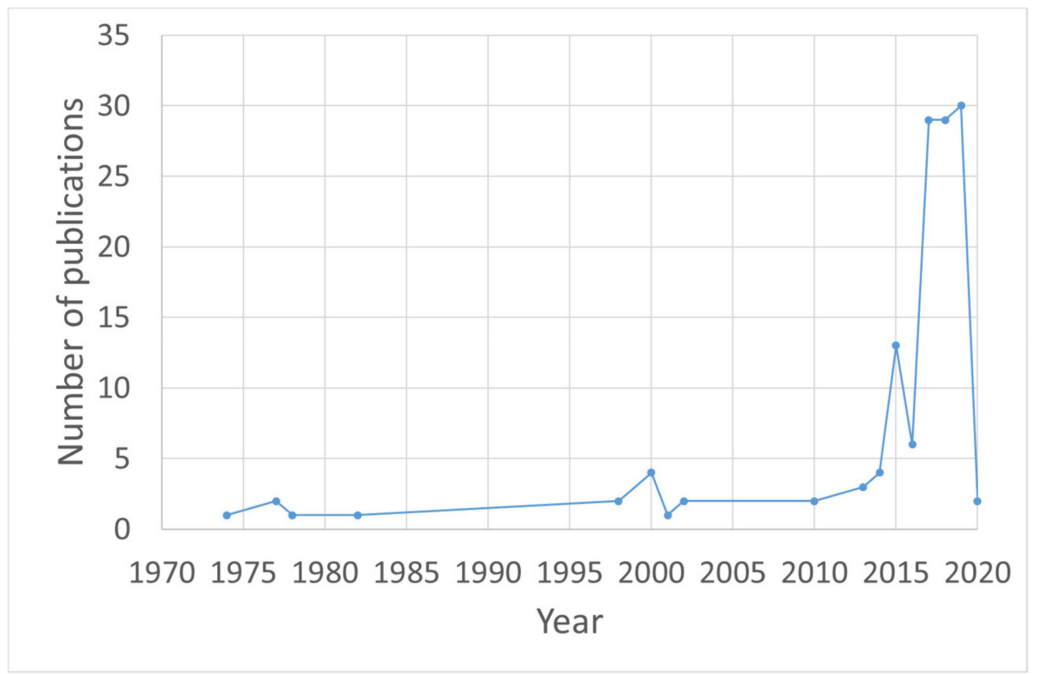

Figure 3. Number of publications per year in the period 1974-2020.

\subsection{Document Type of Publications}

Figure 4 shows the number of publications contained in the Scopus database, divided by type of document. The figure clearly shows that the highest number of publications were categorized as articles and conference papers (75 and 48 documents, respectively). Reviews, book chapters, conference reviews, and notes covered only a small portion of the total documents published.

The results of the bibliometric analysis with the query selected gave a total number of 38 different journals that contained publications related to LAES. Figure 5 shows the number of publications of journals and proceedings that contained at least two documents. Applied Energy was the journal that contained more publications related to LAES (21 publications), followed by Energy Procedia (18 publications). Other journals with a relevant number of publications were Energy (10 publications) and Applied Thermal Engineering (six publications). The four studies published in the Transaction of the Japan Society of Mechanical Engineering included the one carried out between the years 1998 and 2002 by Mitsubishi-Hitachi. 


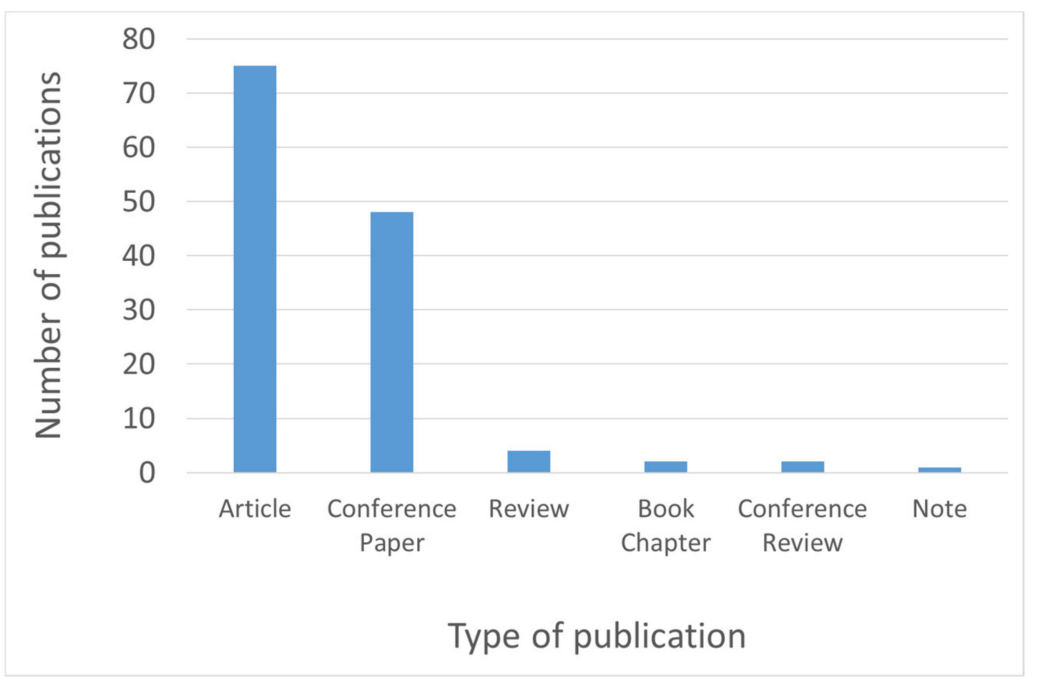

Figure 4. Type and number of publications.

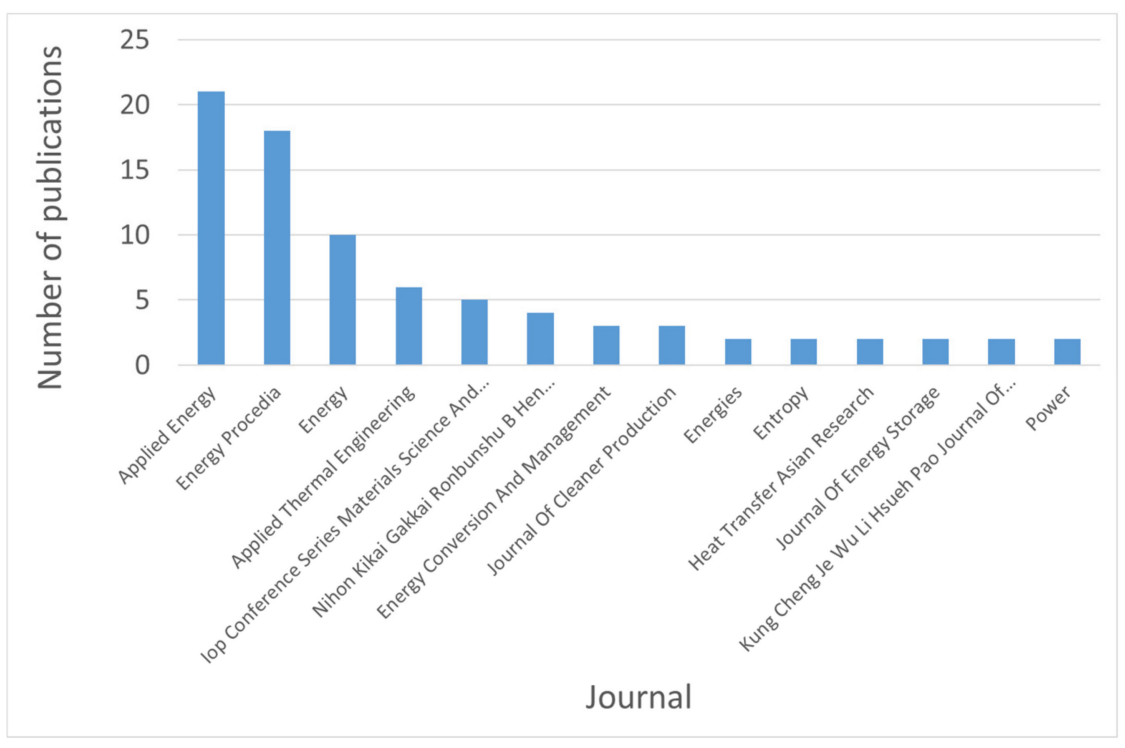

Figure 5. Journals with publications in the topic of study.

Table 1 shows the main characteristics of the journals and proceedings that contained at least two articles. Most articles were published in high-quality journals (Q1) without open access. Transactions of the Japan Society of Mechanical Engineers had the lowest category (Q4). Applied Energy, which contained the most publications, had the highest impact factor amongst the other journals shown in Table 1. It is worth noticing that a high number of documents on LAES have been published in conference proceedings, highlighting the fact that a portion of the material available can be checked out in open access form. However, open access journals excluded from the proceedings (Energies and Entropy) contained only a few publications.

Figure 6 shows the distribution of the publications by subject area based on the output given by Scopus. The subject was mainly affected by the type of journal in which each document was published. Engineering and energy represented the main subjects covering $33 \%$ and $29 \%$, respectively, of the total output. Another large portion relied on environmental science, which covered $15 \%$, followed by physics and astronomy (8\%). Only a smaller portion (3\%) included computer science, material science, and chemical engineering. 
Table 1. List and characteristics of the journals with a minimum of two publications.

\begin{tabular}{ccccc}
\hline Journal & $\begin{array}{c}\text { Number of } \\
\text { Publications in } \\
\text { this Query }\end{array}$ & Category & $\begin{array}{c}\text { Impact Factor } \\
\text { (in 2018) }\end{array}$ & Full Open Access \\
\hline Applied Energy & 21 & $\mathrm{Q} 1$ & 8.26 & No \\
\hline Energy Procedia & 18 & - & - & Yes \\
\hline Energy & 10 & $\mathrm{Q} 1$ & 5.53 & No \\
\hline Applied Thermal Engineering & 6 & $\mathrm{Q} 1$ & 4.02 & No \\
\hline $\begin{array}{c}\text { IOP Conference Series Materials Science } \\
\text { And Engineering }\end{array}$ & 5 & - & - & Yes \\
\hline $\begin{array}{c}\text { Nihon Kikai Gakkai Ronbunshu B Hen } \\
\text { Transactions Of The Japan Society Of } \\
\text { Mechanical Engineers Part B }\end{array}$ & 4 & - & - & Yes \\
\hline Energy Conversion And Management & 3 & $\mathrm{Q} 1$ & 7.18 & No \\
\hline Journal Of Cleaner Production & 3 & $\mathrm{Q} 1$ & 7.32 & Yes \\
\hline Energies & 2 & $\mathrm{Q} 2$ & 2.67 & No \\
\hline Entropy & 2 & $\mathrm{Q} 2$ & 2.30 & No \\
\hline Heat Transfer Asian Research & 2 & - & - & No \\
\hline Journal of Energy Storage & 2 & $\mathrm{Q} 2$ & 3.51 & - \\
\hline Kung Cheng Je Wu Li Hsueh Pao Journal & 2 & - & - & - \\
\hline Of Engineering Thermophysics & 2 & - & - & Yes \\
\hline Power & 2 & - & \\
\hline Proceedings Of The ASME Turbo Expo & & - & & \\
\hline
\end{tabular}

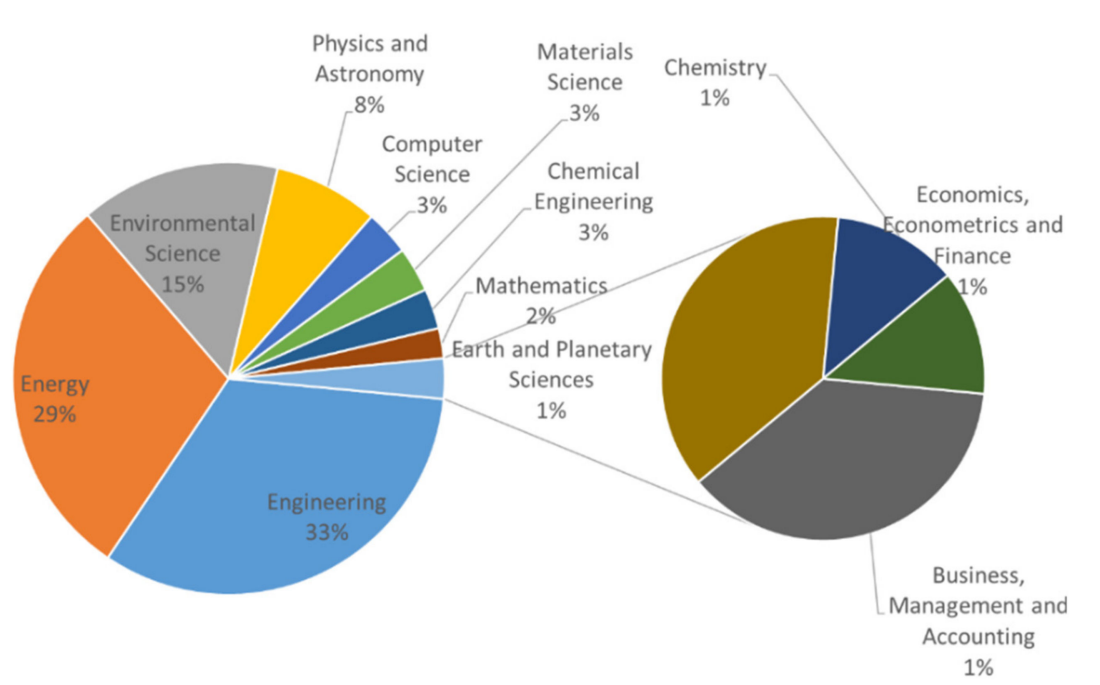

Figure 6. Percentage distribution of the subject area of the journals.

\subsection{Distribution of Publications by Institution}

As above-mentioned, the first studies regarding LAES appeared between 1974 and 2002. Until 2010, when the trend of publication started to grow, only a few institutions worked on the topic of LAES. It is worth commenting that it was not possible to find the institution of some of the authors involved in the earliest publications (from the year 1974 to 1982). Table 2 shows the top 10 institutions with more documents published on LAES. From the table, it is possible to note that most of the institutions included in the top 10 were universities, but the presence of Hitachi Ltd. must be pointed out as they authored all publications from 1998 to 2002. It is worth mentioning that Yonsei University and Cornell University are not reported in Table 2. Indeed, these institutions, active in the topic of LAES [34,35], often use the terminology "cryogenic energy storage" to name the same technology, which, as mentioned in the methodology, was not included in the query selected. 
Table 2. Top 10 institutions and their corresponding country.

\begin{tabular}{ccc}
\hline Affiliation & Country & Publications \\
\hline University of Birmingham & United Kingdom & 25 \\
Nanyang Technological University, ERI@N & Singapore & 12 \\
University of Chinese Academy of Sciences & China & 11 \\
Università Politecnica delle Marche & Italy & 9 \\
Hitachi, Ltd. & Japan & 7 \\
Technical University of Berlin & Germany & 5 \\
University of Brighton & United Kingdom & 4 \\
University Science and Technology Beijing & China & 4 \\
Tsinghua University & China & 4 \\
Università di Pisa & Italy & 4 \\
\hline
\end{tabular}

Figure 7 shows the number of publications of the top 10 institutions that published more documents from 2009 to 2019. In this case, the entities that belonged to the same institution were grouped together as well as the institutions with a similar name. In this case, the University of the Chinese Academic of Sciences contained publications with authors from the Chinese Academy of Sciences and the Technical Institute of Physics and Chemistry Chinese Academy of Sciences. Nanyang Technological University contained works from the School of Mechanical Engineering and Energy Research Institute @NTU. The results showed that in the last three years, most of the documents were produced by the University of Birmingham, with a peak of 10 publications in 2017. In the same year, Nanyang Technological University (including ERI@N) and Università Politecnica delle Marche started to work on the topic of LAES, producing a relevant number of publications compared to the other institutions. It is interesting to note in Figure 7, that in 2018, the number of studies published by those last three institutions decreased when compared to the previous year, to rise again in 2019.

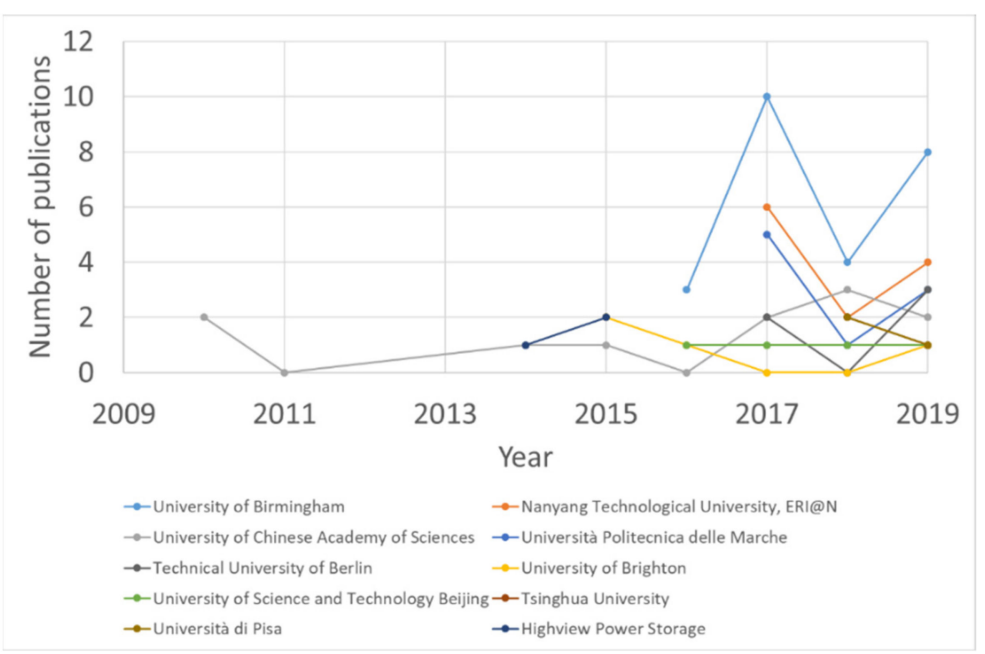

Figure 7. Trend of publications of the top 10 institutions between 2009 and 2019 .

Other recent institutions that have shown interest in the topic in recent years are the Technical University of Berlin, University of Science and Technology of Beijing, Tsinghua University, Università di Pisa, and University of Brighton. The company Highview Power Storage only appeared in the results in 2014 and 2015 with a total of three publications. Figure 7 also shows that the Chinese Academy of Sciences started to publish on LAES in 2010 with two publications, without producing further outputs until 2014. Up until 2019, the Chinese Academy of Sciences have shown a constant interest in the topic of LAES, with a maximum of three documents published in 2018. 


\subsection{Countries Distribution}

Figure 8 shows a world map highlighting the countries that published more studies on LAES in the period related to 1974-2020 (updated to November 2019) using the Scopus database. The results showed that only a few countries are involved in the topic selected. The United Kingdom had the strongest output of publications, highlighted by the darker color in the map. Indeed, in recent years, the United Kingdom has been identified as the core of the LAES technology, and hosts the first $350 \mathrm{~kW} / 2.5 \mathrm{MWh}$ pilot plant in the world, developed first by Highview Power Storage at Slough and now relocated to the University of Birmingham [32,33]. Furthermore, another grid-scale $5 \mathrm{MW} / 15 \mathrm{MWh}$ plant was launched in 2018 in Bury (Manchester) by Highview Power and Viridor [36]. The second country with the highest number of publications highlighted by the map in Figure 8 was China, followed by Italy and Germany.

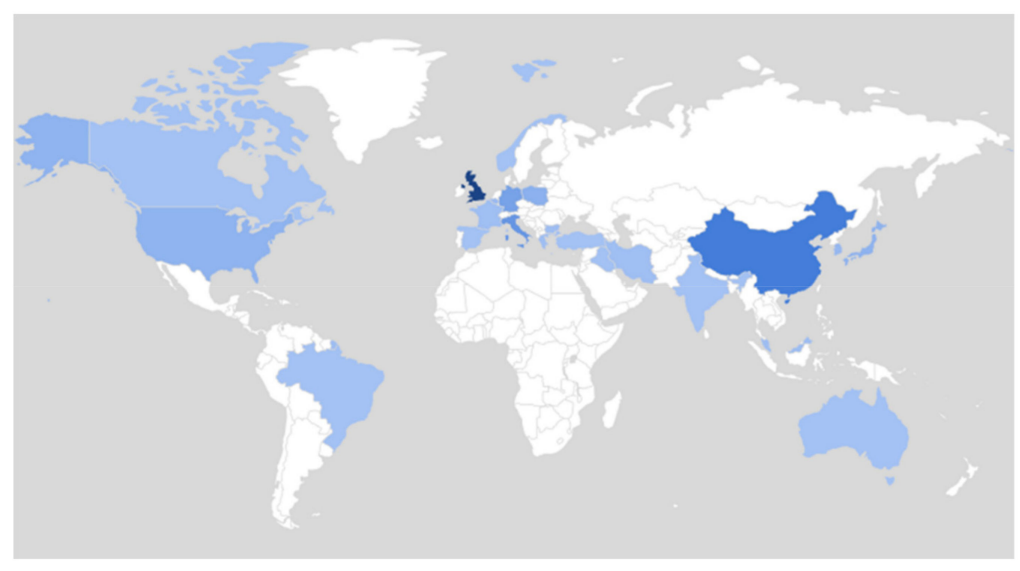

Figure 8. World map of the publications distributed for each country.

Figure 9 shows the number of publications for each country, also highlighting the number of publications per millions of inhabitants. It is interesting to note that, although it was not the strongest country in the world map in terms of the number of publications, Singapore had the highest density of documents published considering the population of the country. The figure also shows that the United Kingdom was the second country to have the highest number of publications per millions of inhabitants, while China had one of the lowest values due to the high density of population.

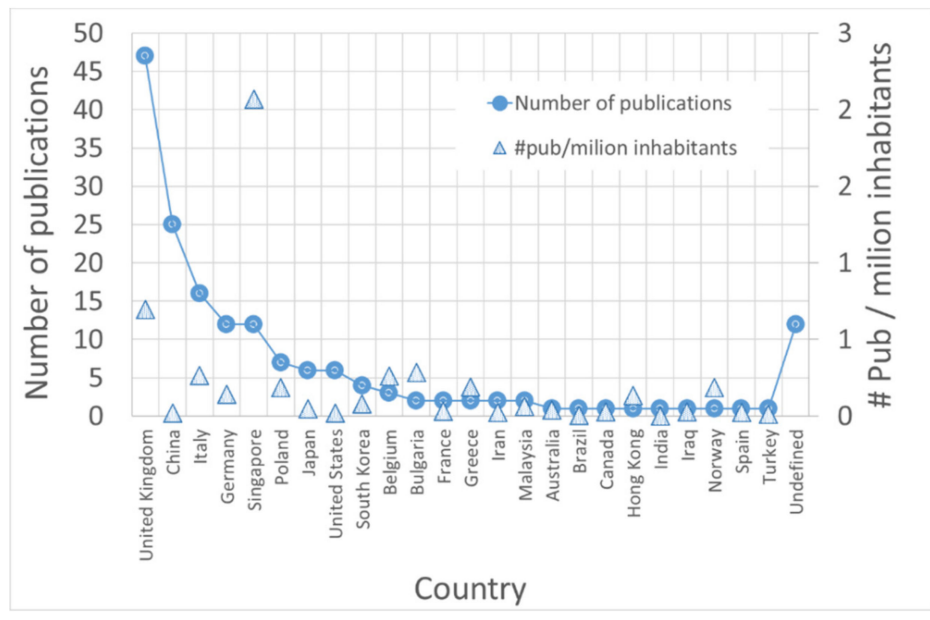

Figure 9. Number of publications for each country and ratio of the number of publications per millions of inhabitants. 
Figure 10 shows the results obtained by elaborating on the data from Scopus with the software VOSviewer. In particular, the figure shows the links between the different countries and their relation in terms of co-authorship on the work published. This figure shows that there were a lot of countries that were not linked to each other. In the center of the figure, two main clusters can be noted. The first cluster (in red) includes the United Kingdom and China, who were connected with a strong relationship marked with a thick line. The second cluster (in green) included the main countries of Italy and Singapore that, also in this case, they were strongly linked together. It is interesting to note that these two clusters were linked together, connecting the United Kingdom with both Italy and Singapore. A third smaller cluster can be detected at the bottom of the figure in blue, linking Germany, Greece, and Poland.

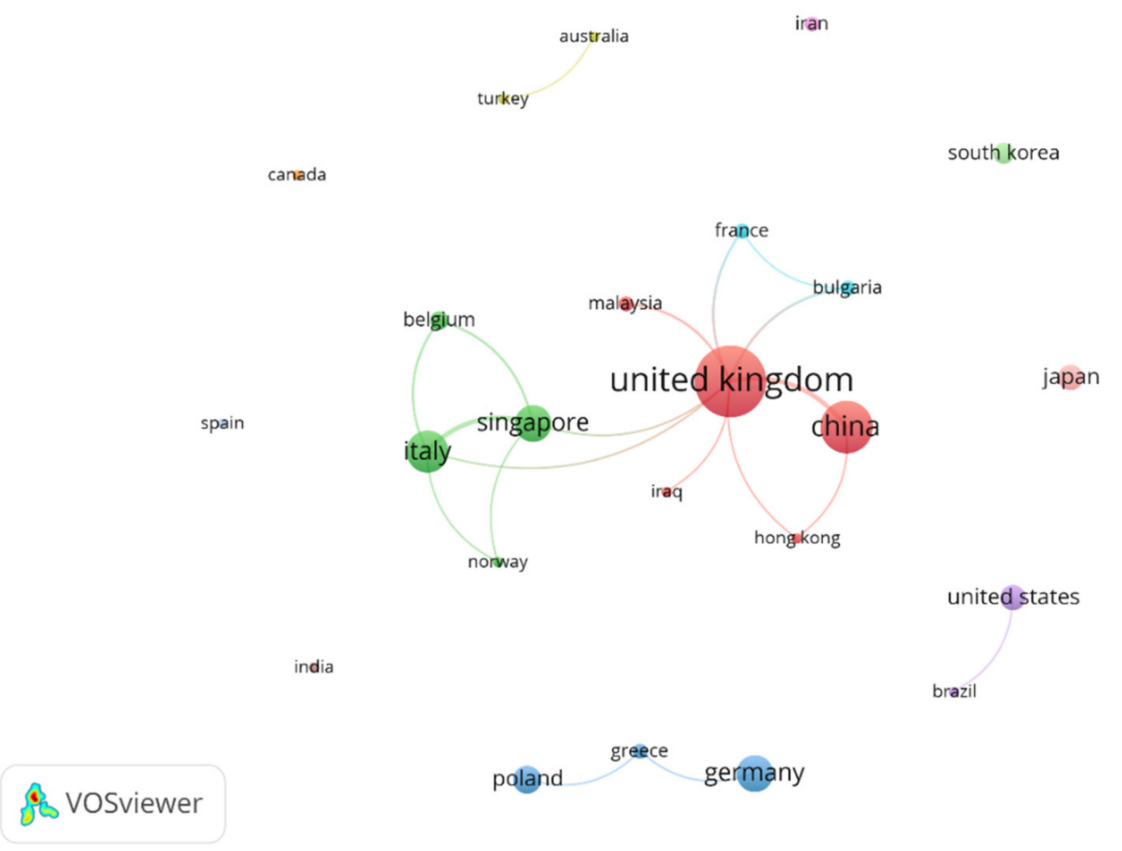

Figure 10. Network of the different countries elaborated with VOSviewer.

\subsection{Authorship Analysis}

The top 10 authors who have published on the topic of LAES, according to the Scopus database, are reported in Table 3. In this case, some of the authors were present in the database with two different names, therefore in order to have a fair comparison, they were identified and, if they corresponded to the same author, grouped together. In this case, the real h-index reported in Scopus and the number of documents cannot correspond to the real one due to the different names. Table 3 shows that authors belonging to institutions from the UK published the majority of the documents present in the database. Yulong Ding leads the ranking with 16 documents, followed by Yongliang Li with 13 documents. These two authors belong to the same institution, the University of Birmingham, and have a total number of 351 and 76 documents and an h-index of 54 and 18, respectively. The third ranking author was Alessandro Romagnoli from Nanyang Technological University of Singapore (and Energy Research institute @NTU) with 12 publications. It is also possible to note that for some of the authors (Xiaodong Peng, Alessio Tafone, Emiliano Borri, and K. Chino), the total number of publications almost corresponded to the number of publications on the topic of LAES, indicating that this is their main research field.

Figure 11 shows the links between the different authors with a minimum of two publications, obtained by elaborating the data with the help of the software VOSviewer. In this case, it was possible to identify two main clusters. In the first cluster (in red), there were authors linked to Yulong Ding, where the strongest links were with Yongliang Li, Xiaohui She, and Xiaodong Peng from the University of Birmingham [37-39]. In the second cluster (in purple), Alessandro Romagnoli was strongly related to Gabriele Comodi and Emiliano Borri from Università Politecnica delle Marche, 
and Alessio Tafone [40,41] from Nanyang Technological University, which highlights the strong link between Italy and Singapore. The other cluster included Chino K. and Araki H. from to Hitachi Ltd. [29] (in pink); Giglioli R., Desideri U., Paganucci F., Barsali S., Pasini G., and Antonelli, M. [42-44] from the University of Pisa (in yellow); and Evans J., Damas A., Brown T., Negro D., Varga L. and Hu Y. Fikiin K. from different institutions that belong to the CryoHub project [45].

Table 3. List and details of the top 10 authors including institution, country, total document on Scopus, and h-index.

\begin{tabular}{|c|c|c|c|c|c|}
\hline Author & Institution & Country & $\begin{array}{l}\text { Publications } \\
\text { on the LAES }\end{array}$ & $\begin{array}{c}\text { Total } \\
\text { Documents }\end{array}$ & $\begin{array}{l}h \text {-Index in } \\
\text { Scopus }\end{array}$ \\
\hline Ding, $\mathrm{Y}^{*}$ & $\begin{array}{l}\text { University of } \\
\text { Birmingham }\end{array}$ & UK & 16 & $(300+51)$ & 54 \\
\hline $\mathrm{Li}, \mathrm{Y}$. & $\begin{array}{l}\text { University of } \\
\text { Birmingham }\end{array}$ & UK & 13 & 76 & 18 \\
\hline Romagnoli, A. & $\begin{array}{c}\text { Nanyang Technological } \\
\text { University, ER }\end{array}$ & Singapore & 12 & 125 & 17 \\
\hline Comodi, G. & $\begin{array}{l}\text { Università Politecnica } \\
\text { delle Marche }\end{array}$ & Italy & 9 & 71 & 17 \\
\hline Peng, $X$. & $\begin{array}{l}\text { University of } \\
\text { Birmingham }\end{array}$ & UK & 9 & 14 & 5 \\
\hline She, $X$. & $\begin{array}{l}\text { University of } \\
\text { Birmingham }\end{array}$ & UK & 9 & 34 & 11 \\
\hline Tafone, A. & $\begin{array}{l}\text { Nanyang Technological } \\
\text { University, ER }\end{array}$ & Singapore & 9 & 12 & 4 \\
\hline Borri, E. & $\begin{array}{c}\text { Università Politecnica } \\
\text { delle Marche }\end{array}$ & Italy & 8 & 9 & 4 \\
\hline Chino, K. & Hitachi, Ltd. & Japan & 8 & 8 & 2 \\
\hline Al-Dadah, R.* & $\begin{array}{l}\text { University of } \\
\text { Birmingham }\end{array}$ & UK & 6 & 135 & 22 \\
\hline
\end{tabular}

(* authors present in the database with two different names.).

\& Vosviewer

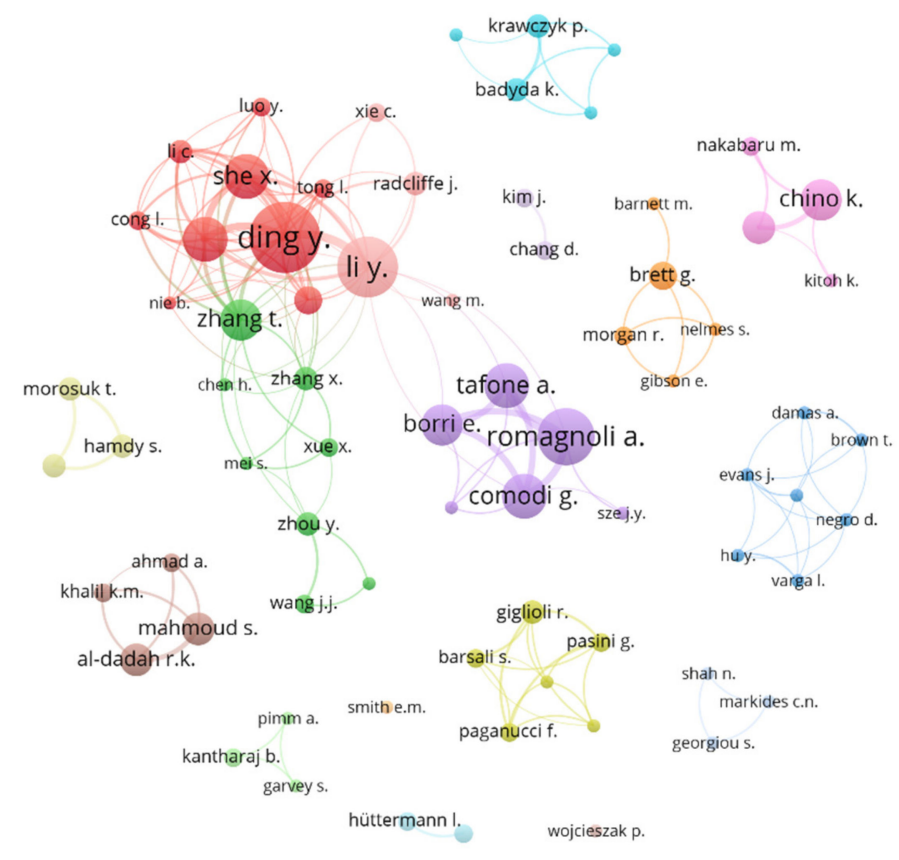

Figure 11. Network of the different authors elaborated with VOSviewer. 


\subsection{Analysis of Keywords}

The analysis of keywords was an important aspect of this research to identify the state-of-the-art, scope, and the objectives of the research that had been done and future prospective; moreover, research gaps could be identified. Table 4 shows the keywords found in the Scopus database from all of the documents considered for the present bibliometric analysis. In this case, the keywords reported in the table were divided into four sections. From the keywords, it was possible to observe that between the keywords related to energy storage, it appeared as compressed air energy storage (CAES). Indeed, this technology is often used to compare the LAES $[46,47]$. From the keywords related to the type of study, it was possible to note that most of the approaches were mainly theoretical such as "thermodynamics", "exergy analysis", and "economic analysis". With regard to energy systems and components, it was possible to find some keywords related to thermal energy storage such as "packed bed" and "storage (materials)".

Table 4. List of the main keywords divided in different categories from the Scopus database.

\begin{tabular}{cccc}
\hline Related to Energy Storage & Related to the Type of Study & $\begin{array}{c}\text { Related to the Energy } \\
\text { Systems and } \\
\text { Components }\end{array}$ & Others \\
\hline Cryogenic energy storage & Thermodynamics & Rankine cycle & Liquefied gases \\
\hline Energy storage & Exergy analysis & Storage (materials) & Waste heat \\
\hline Electric energy storage & Economic analysis & Pressure vessels & Combustion \\
\hline Liquid air energy storage & Optimization & Packed bed & Liquefied natural gas \\
\hline Compressed air energy storage & Cost benefit analysis & Gas turbine & - \\
\hline- & Environmental impact & Heat exchangers & - \\
\hline- & Sustainable development & Cooling systems & - \\
\hline- & Sensitivity analysis & Pilot plants & - \\
\hline- & - & Organic Rankine cycle & -
\end{tabular}

Figure 12 shows the co-occurrence map of the keywords obtained by elaborating the output from the database Scopus with VOSviewer. The different density of colors and size of the character in the map highlights the frequency that the keyword appears in the different publications. The figure shows that the keyword "liquid air energy storage" had less relevance than the word "energy storage" and "liquefied gases". This can probably be attributed to the presence of the keyword "cryogenic energy storage", which is sometimes used to represent the same technology.

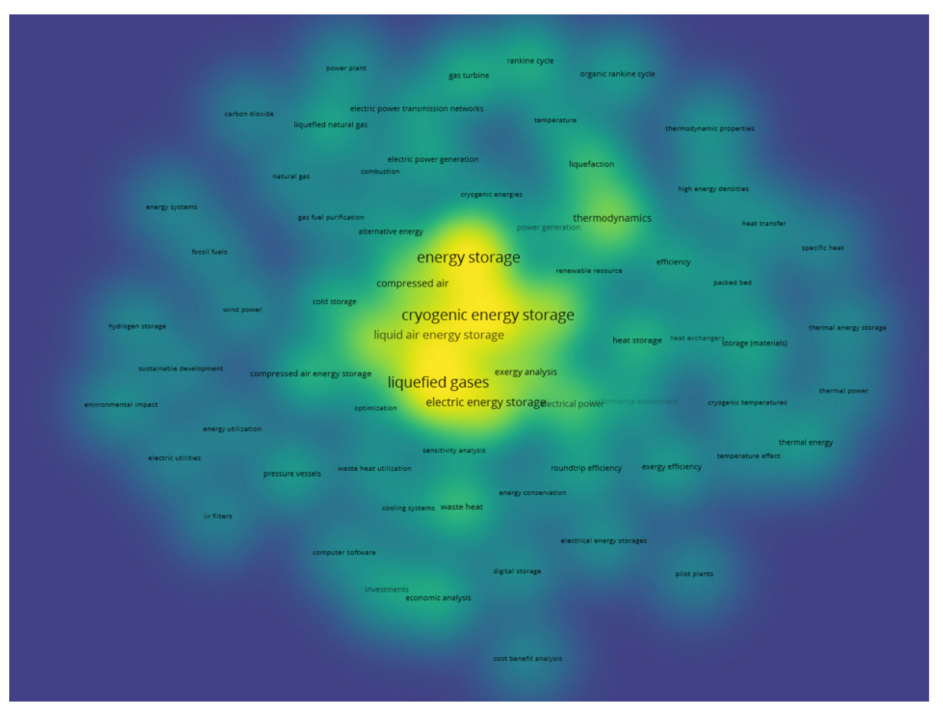

Figure 12. Co-occurrence of the keywords elaborated with VOSviewer. 
Other frequent keywords that can be identified from the map shown in Figure 12, are "renewable energy", "liquid air", "compressed air", "energy efficiency", "exergy", "compressed air energy storage", "thermodynamics", and "liquefaction". The link between the different keywords is shown in Figure 13.

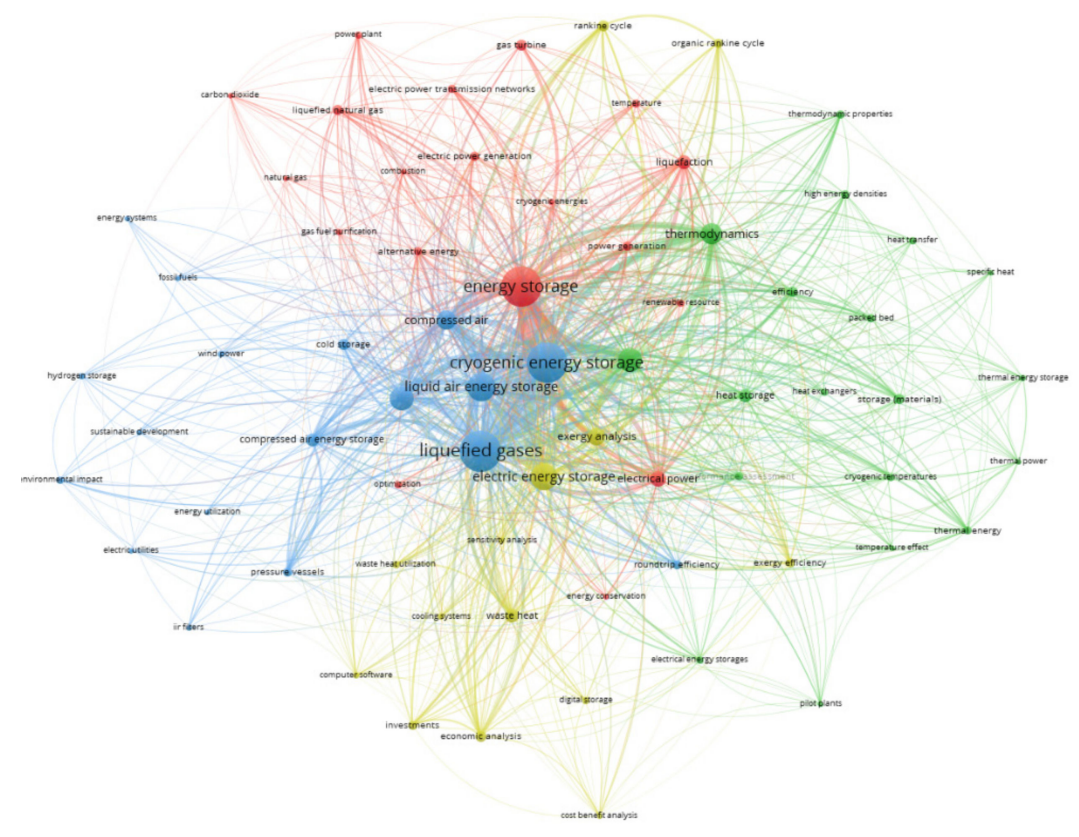

Figure 13. Co-occurrence and link of the keywords elaborated with VOSviewer.

In particular, Figure 13 shows that the keywords are divided into different clusters, highlighted by the different colors. In particular, the keywords "liquefied gases", "liquid air energy storage", and "cryogenic energy storage" were all included in the same cluster with a strong relation. Highlighting the keyword "liquid air energy storage" (Figure 14), it is possible to note that this keyword was strongly related to the keywords "energy storage", "cryogenic energy storage", "liquefied gases", "compressed air", "compressed air energy storage", and "energy efficiency". It is also interesting to note that "liquid air energy storage" had a strong relation with "exergy" and "thermodynamics". Indeed, thermodynamics analysis and exergy analysis represent the most common approaches in the study of LAES systems, and terms such as thermodynamic efficiency and exergetic efficiency are often used as the main index of comparison with other energy storage technologies. Furthermore, increasing the thermodynamic efficiency of the LAES is an important target of the technology feasibility, since it represents the main disadvantage when compared to other technologies. Indeed, roundtrip efficiency for large scale systems can be estimated to be around 50\% [36], which is lower than other large scale technologies such as compressed air energy storage and pumped electric energy storage, whose roundtrip efficiency can be estimated around $70 \%$.

Analyzing the keyword "energy storage", as shown in Figure 15, it is interesting to see the keywords "alternative energy", "liquefaction", "natural gas", "liquefied natural gas", and "electric power generation" in the same cluster. The link between these keywords can be explained since the LAES is often classified as an alternative storage solution to the actual large scale energy storage technologies. Furthermore, since cryogenics is involved as a storage energy vector, LAES is characterized by the advantage that it can be integrated with waste cold energy resources such as the regasification of liquefied natural gas $[8,37,48]$. Other connections, external to the energy storage cluster, were with "electric energy storage", "liquefaction", "renewable energy", and "thermodynamics". 


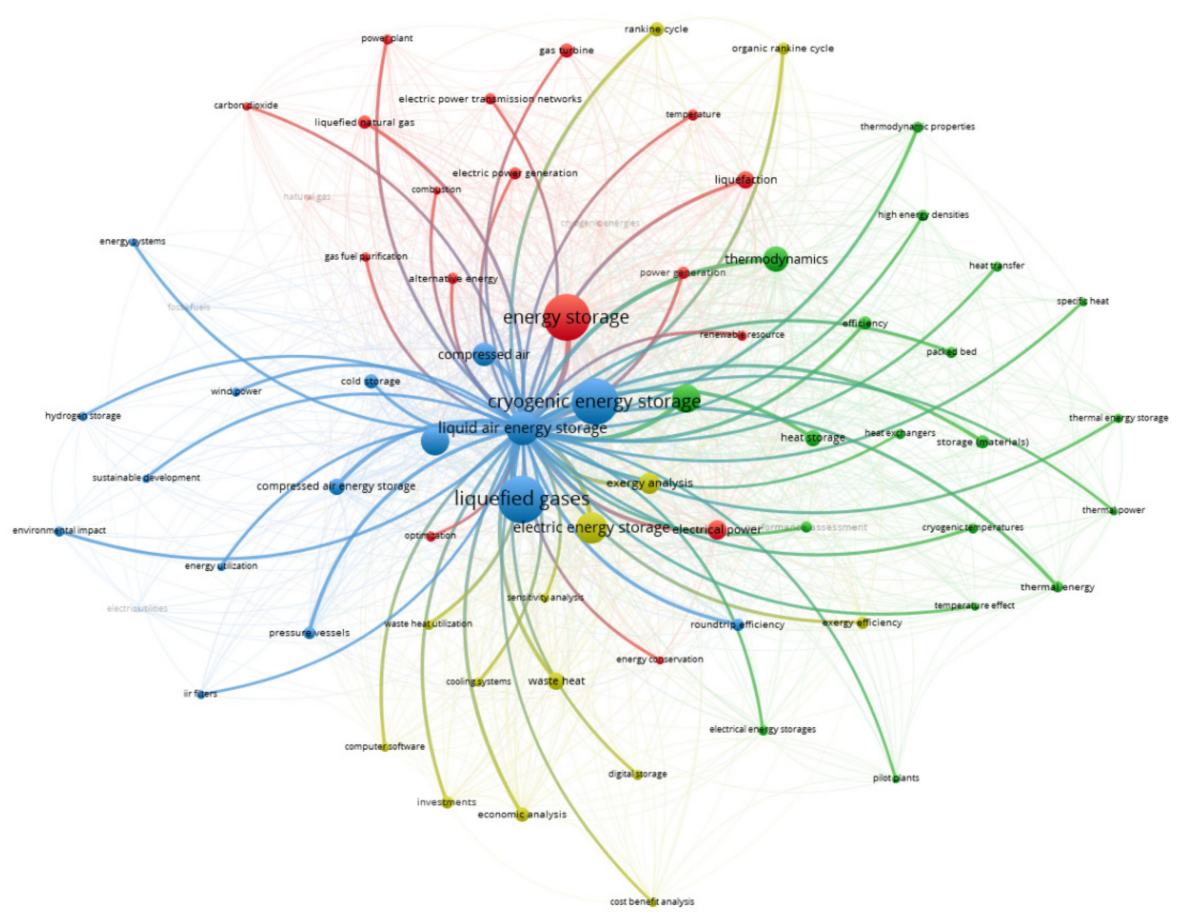

Figure 14. Co-occurrence and link of the keyword "liquid air energy storage" elaborated with VOSviewer.

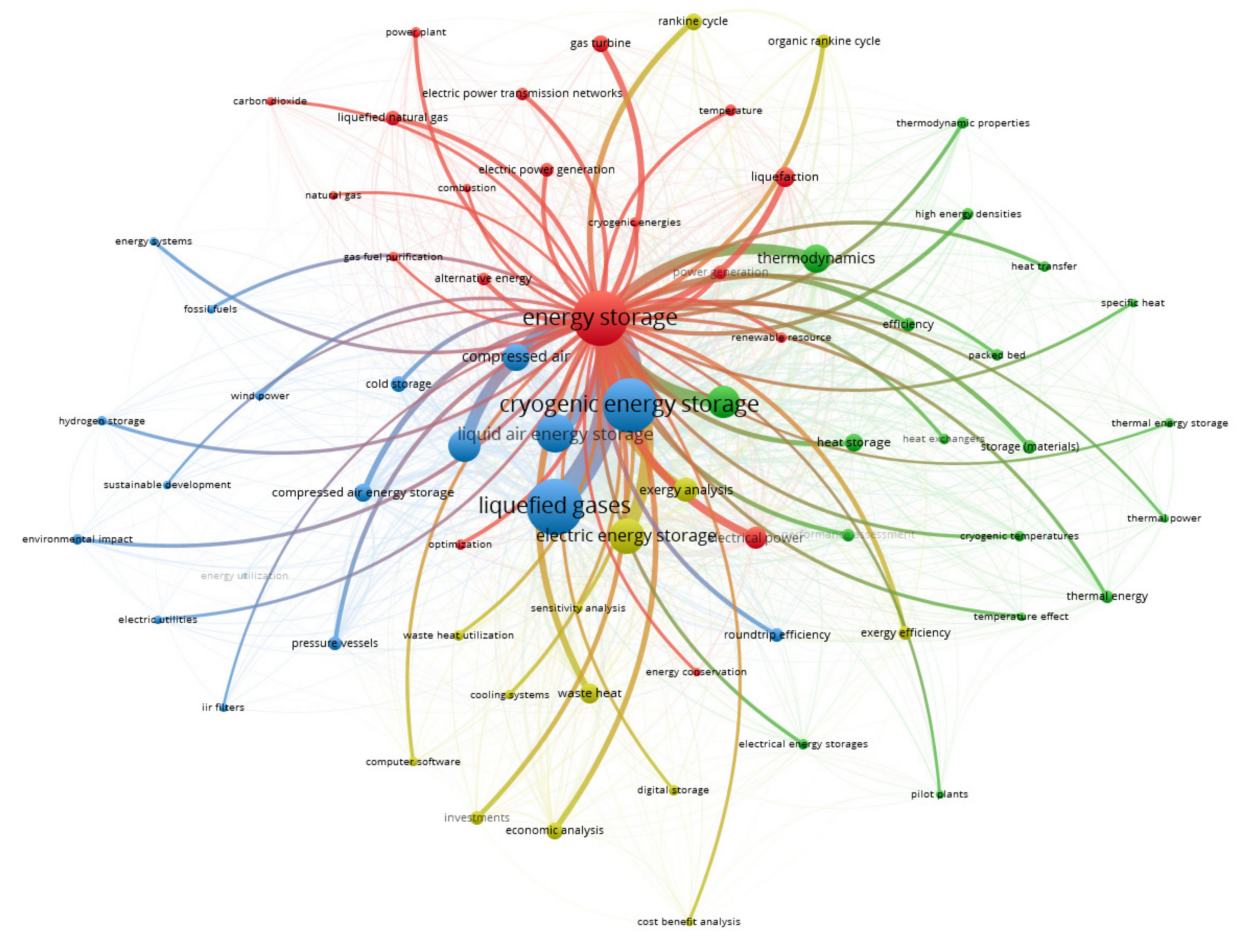

Figure 15. Co-occurrence and link of the keyword "energy storage" elaborated with VOSviewer.

Figure 16 shows the overlay visualization of the different keywords contained in the documents. This is an interesting approach to describe the frequency of the keywords in the different years (from 2015 to 2018) for the query used. From the figure, it is possible to see that during 2015/2016, the most popular keywords were "energy storage", "liquefaction", "electric energy storage", "electric power generation", and "gas turbine". The keywords "thermodynamics", "compressed air energy storage", "waste heat", and "economic analysis" were popular in documents published around 2017. 
These keywords highlight that most of the work published in that period investigated the LAES mainly through thermodynamic analysis [49,50], with some studies that considered the economic aspect [51]. Recent publications on LAES contained keywords such as "exergy analysis", "packed bed", "cold storage", "exergy efficiency", and "organic Rankine cycle". The first keyword points out that recent studies have focused on a different thermodynamic approach based on second law analysis with the aim to evaluate the exergy efficiency of the system $[52,53]$. It is worth noting that the words "organic Rankine cycle", "packed bed", and "cold storage" are all concepts related to the use of thermal energy. Indeed, all the studies affirm that the efficiency of the LAES can be increased by recovering the thermal energy wasted by the system $[39,54]$. Furthermore, the thermal energy released is both at high temperature (energy wasted during the compression when LAES is charging) and cryogenic temperature (energy wasted the liquid air regasification process when LAES is discharging). In some LAES systems proposed in the literature, the waste heat at high temperature is recovered and used in the same system [49]. The keyword "organic Rankine cycle", linked to works published after 2018, highlights an interesting trend in the research of LAES with studies that aim for the integration of the two systems as a waste heat recovery solution $[41,55]$. On the other hand, the recovery of the cold energy by LAES is crucial to achieve a reasonable value of efficiency [12]. Indeed, this is mainly reused to help the liquefaction of the liquid air when the system is charged, thus increasing the efficiency. The presence of the keywords "packed bed", and "cold storage", linked to studies after 2018, highlights an interesting trend to investigate efficient cold storage solutions (including packed bed configuration) integrated with the LAES technology [56,57].

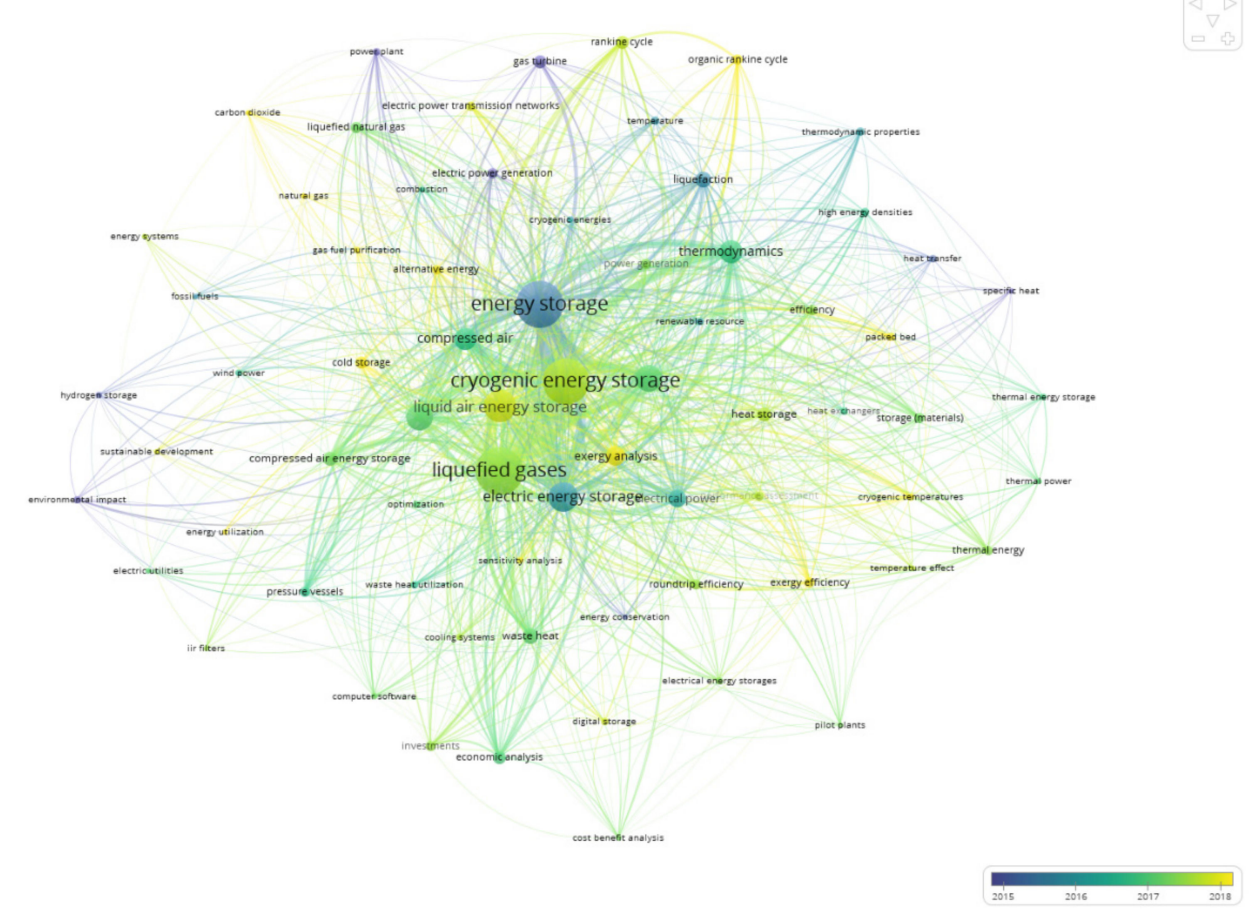

Figure 16. Co-occurrence and overlay visualization of the keyword elaborated with VOSviewer.

\section{Conclusions}

In recent years, LAES has gained momentum as an alternative energy storage technology characterized by high energy density and no geological constraints with the ability to be integrated with high-grade waste cold or waste heat resources. This has led to a rapid increase of scientific production on the topic of LAES, with a growing number of worldwide institutions investigating the potential of this technology. Although the first publication on LAES appeared on 1974, the trend on scientific literature started to rapidly increase after a project started in 2008 with the realization of the 
first LAES pilot plant located at the University of Birmingham in the United Kingdom. Nevertheless, this was the institution with the highest number of works published on LAES. The highest number of publications on this topic was contained in Q1 scientific journals and conference proceedings in the category of "engineering" and "energy". Applying bibliometric techniques in the analysis of the keywords, the most relevant aspects of the current research were analyzed to identify research gaps and future trends that could be used to inspire future research.

The main conclusions that can be drawn regarding the research on LAES, supported by the bibliometric analysis carried out in this review, can be summarized as follows:

- Most of the approaches in the study of LAES have been based on thermodynamic and exergy analysis of the system with the aim to estimate the efficiency of the LAES and propose solutions to increase the system performance, which is currently the major drawback of this technology.

- The keyword analysis also showed that part of the research on the topic of LAES was interested in investigating the economic feasibility of the system. However, the relevance of keywords related to the economic aspect was lower compared to terms related to the thermodynamic analysis, identifying the first research gap.

- The last trend in the research of LAES aims for the integration of this technology with other external systems that allow for the exploitation of waste thermal energy. The most common system integrated to the LAES as a waste heat recovery solution is the organic Rankine cycle (ORC), while at low temperatures, different studies in the literature have used the LAES technology to exploit the waste cold thermal energy from cryogenic processes such as in liquefied natural gas regasification plants. Studies on how to efficiently store the cold and the hot energy wasted from the LAES represent another trend in the last research. Indeed, recovering cold energy is demonstrated to be crucial to increase the efficiency of the liquefaction process. On the other hand, the recovery of the waste heat can improve the discharge performance. Therefore, the research of new storage materials and thermal energy storage designed to efficiently store the cold and hot energy, represents a hotspot that future research should take into account to improve the LAES technology.

- The analysis of the keywords lacked terms related to experimental studies that demonstrate the real performance of the system. This shows that this aspect is weak and has not been deeply investigated. This represents the main gap that future scientific research should fill in to reach a significant milestone in the LAES technology.

Author Contributions: Conceptualization, E.B. and L.F.C.; Methodology, L.F.C., E.B., and G.Z.; Investigation, E.B. L.F.C., and G.Z.; Writing - original draft preparation, E.B. and A.T.; Writing—review and editing, L.F.C., E.B., A.T., A.R., and G.C.; Visualization, E.B. and L.F.C.; Project administration, L.F.C.; Funding acquisition, L.F.C. All authors have read and agreed to the published version of the manuscript.

Funding: This work was partially funded by the Ministerio de Ciencia, Innovación y Universidades de España (RTI2018-093849-B-C31-MCIU/AEI/FEDER, UE). This work was partially funded by the Ministerio de Ciencia, Innovación y Universidades - Agencia Estatal de Investigación (AEI) (RED2018-102431-T).

Acknowledgments: The authors at the University of Lleida would like to thank the Catalan Government for the quality accreditation given to their research group GREiA (2017 SGR 1537). GREiA is a certified agent TECNIO in the category of technology developers from the Government of Catalonia. This work was partially supported by ICREA under the ICREA Academia program.

Conflicts of Interest: The authors declare no conflicts of interest.

\section{References}

1. Int. Energy Agency. World Energy Outlook 2019; Int. Energy Agency: Paris, France, 2019.

2. Zhang, X. Energy Solutions to Combat Global Warming; Springer International Publishing: Cham, Switzerland, 2017; ISBN 978-3-319-26948-1.

3. Anil, M.; Saygin, D.; Miketa, A.; Gielen, D.; Nicholas, W. The True Cost of Fossil Fuels: Saving on the Externalities of Air Pollution And Climate Change; International Renewable Energy Agency: Abu Dhabi, UAE, 2016. 
4. Lott, M.C.; Kim, S.-I.; Tam, C.; Houssin, D.; Gagné, J.F. Technology Roadmap: Energy Storage; Int. Energy Agency (IEA): Paris, France, 2014.

5. Chen, H.; Cong, T.N.; Yang, W.; Tan, C.; Li, Y.; Ding, Y. Progress in electrical energy storage system: A critical review. Prog. Nat. Sci. 2009, 19, 291-312. [CrossRef]

6. Luo, X.; Wang, J.; Dooner, M.; Clarke, J. Overview of current development in electrical energy storage technologies and the application potential in power system operation q. Appl. Energy 2015, 137, 511-536. [CrossRef]

7. Morgan, R.; Nelmes, S.; Gibson, E.; Brett, G. An analysis of a large-scale liquid air energy storage system. Proc. Inst. Civ. Eng. 2015, 168, 135-144. [CrossRef]

8. Kim, J.; Noh, Y.; Chang, D. Storage system for distributed-energy generation using liquid air combined with liquefied natural gas. Appl. Energy 2018, 212, 1417-1432. [CrossRef]

9. Tafone, A.; Borri, E.; Li, Y. Techno-economic analysis of a Liquid Air Energy Storage (LAES ) for cooling application in hot climates. Energy Procedia 2016, 105, 4450-4457. [CrossRef]

10. Liquid Air Energy Network. The Cold Economy (Guide); Liquid Air Energy Network: London, UK, 2014; Available online: https://dearman.co.uk/media/reports-guides/ (accessed on 16 April 2020).

11. Comodi, G.; Carducci, F.; Sze, J.Y.; Balamurugan, N.; Romagnoli, A. Storing energy for cooling demand management in tropical climates: A techno-economic comparison between different energy storage technologies. Energy 2017, 121, 676-694. [CrossRef]

12. Tafone, A.; Romagnoli, A.; Borri, E.; Comodi, G. New parametric performance maps for a novel sizing and selection methodology of a Liquid Air Energy Storage system. Appl. Energy 2019, 250, 1641-1656. [CrossRef]

13. van Raan, A.F.J. For your citations only? Hot topics in bibliometric analysis. Meas. Interdiscip. Res. Perspect. 2005, 3, 50-62. [CrossRef]

14. Mao, G.; Zou, H.; Chen, G.; Du, H.; Zuo, J. Past, current and future of biomass energy research: A bibliometric analysis. Renew. Sustain. Energy Rev. 2015, 52, 1823-1833. [CrossRef]

15. Calderón, A.; Barreneche, C.; Hernández-Valle, K.; Galindo, E.; Segarra, M.; Fernández, A.I. Where is Thermal Energy Storage (TES) research going?-A bibliometric analysis. Sol. Energy 2019, 200, 37-50. [CrossRef]

16. Bartolini, M.; Bottani, E.; Grosse, E.H. Green warehousing: Systematic literature review and bibliometric analysis. J. Clean. Prod. 2019, 226, 242-258. [CrossRef]

17. Du, H.; Li, N.; Brown, M.A.; Peng, Y.; Shuai, Y. A bibliographic analysis of recent solar energy literatures: The expansion and evolution of a research field. Renew. Energy 2014, 66, 696-706. [CrossRef]

18. Cabeza, L.F.; Chàfer, M.; Mata, É. Comparative Analysis of Web of Science and Scopus on the Energy Efficiency and Climate Impact of Buildings. Energies 2020, 13, 409. [CrossRef]

19. Falagas, M.E.; Pitsouni, E.I.; Malietzis, G.A.; Pappas, G. Comparison of PubMed, Scopus, web of science, and Google scholar: Strengths and weaknesses. FASEB J. 2008, 22, 338-342. [CrossRef] [PubMed]

20. Lee, I.; Park, J.; Moon, I. Conceptual design and exergy analysis of combined cryogenic energy storage and LNG regasification processes: Cold and power integration. Energy 2017, 140, 106-115. [CrossRef]

21. Van Eck, N.; Waltman, L. Software survey: VOSviewer, a computer program for bibliometric mapping. Scientometrics 2010, 84, 523-538. [CrossRef]

22. Shepherd, D.G. A Low-Pollution On-Site, Energy Storage System for Peak-Power Supply. In Proceedings of the ASME 1974 International Gas Turbine Conference and Products Show, Zurich, Switzerland, 30 March-4 April 1974; American Society of Mechanical Engineers Digital Collection: New York, NY, USA, 1974.

23. Smith, E.M. Storage of Electrical Energy Using Supercritical Liquid Air. Proc. Inst. Mech. Eng. 1977, 191, 289-298. [CrossRef]

24. de Marchi Desenzani, P. Remote new energy sources utilization in on-site non-polluting power plant-Liquid air as energy carrier concept and final conversion plant design. In Proceedings of the Alternative Energy Sources Miami International Conference, Miami Beach, FL, USA, 5-7 December 1977; Volume 9, pp. 4091-4103.

25. Dooley, J.L. COMPACT ENERGY STORAGE 82-1696 JL Dooley* and R. Philip Hammond R\&D Associates, Marina del Rey, CA 90291. In Proceedings of the A Collection of Technical Papers: AIAA/EPRI International Conference on Underground Pumped Hydro and Compressed Air Energy Storage, San Francisco, CA, USA, 20-22 September 1982; American Institute of Aeronautics and Astronautics: Reston, VA, USA, 1982; Volume 120, p. 288.

26. Kitou, K.; Fujii, T.; Shiina, K.; Chino, K. Liquid air energy storage system (study of air liquefaction characteristics using a concrete-type cool storage unit). Nippon Kikai Gakkai Ronbunshu B Hen/Trans. Jpn. Soc. Mech. Eng. Part B 2002, 68, 2870-2876. 
27. Araki, H.; Nakabaru, M.; Chino, K. Simulation of heat transfer in the cool storage unit of a liuid-air energy storage system. Heat Transf.-Asian Res. 2002, 31, 284-296. [CrossRef]

28. Araki, H.; Nakabaru, M.; Chino, K. Heat transfer performance of new-style LNG heat exchangers. Nihon Kikai Gakkai Ronbunshu B Hen/Trans. Jpn. Soc. Mech. Eng. Part B 2001, 67, 1451-1458.

29. Araki, H.; Kitoh, K.; Chino, K. Heat transfer in the regenerator of a liquid air energy storage system. American Society of Mechanical Engineers, Advanced Energy Systems Division (Publication) AES 2000, 40, 373-378.

30. Chino, K.; Araki, H. Evaluation of energy storage method using liquid air. Heat Transf. Asian Res. 2000, 29, 347-357. [CrossRef]

31. Kito, K.; Shiina, K.; Chino, K. Liquid air energy storage system (heat transfer characteristics of concrete cool storage unit). Nihon Kikai Gakkai Ronbunshu B Hen/Trans. Jpn. Soc. Mech. Eng. Part B 2000, 66, 1541.

32. Sciacovelli, A.; Smith, D.; Navarro, H.; Li, Y.; Ding, Y. Liquid air energy storage-Operation and performance of the first pilot plant in the world. In Proceedings of the ECOS, Portorož, Slovenia, 19-23 June 2016.

33. Morgan, R.; Nelmes, S.; Gibson, E.; Brett, G. Liquid air energy storage-Analysis and first results from a pilot scale demonstration plant. Appl. Energy 2015, 137, 845-853. [CrossRef]

34. Park, J.; Lee, I.; You, F.; Moon, I. Economic Process Selection of Liquefied Natural Gas Regasification: Power Generation and Energy Storage Applications. Ind. Eng. Chem. Res. 2019, 58, 4946-4956. [CrossRef]

35. Lee, I.; Park, J.; You, F.; Moon, I. A novel cryogenic energy storage system with LNG direct expansion regasification: Design, energy optimization, and exergy analysis. Energy 2019, 173, 691-705. [CrossRef]

36. Highview Power. Available online: https://www.highviewpower.com/ (accessed on 16 April 2020).

37. Peng, X.; She, X.; Li, C.; Luo, Y.; Zhang, T.; Li, Y.; Ding, Y. Liquid air energy storage flexibly coupled with LNG regasification for improving air liquefaction. Appl. Energy 2019, 250, 1190-1201. [CrossRef]

38. She, X.; Zhang, T.; Cong, L.; Peng, X.; Li, C.; Luo, Y.; Ding, Y. Flexible integration of liquid air energy storage with liquefied natural gas regasification for power generation enhancement. Appl. Energy 2019, 251, 113355. [CrossRef]

39. She, X.; Peng, X.; Nie, B.; Leng, G.; Zhang, X.; Weng, L.; Tong, L.; Zheng, L.; Wang, L.; Ding, Y. Enhancement of round trip efficiency of liquid air energy storage through effective utilization of heat of compression. Appl. Energy 2017, 206, 1632-1642. [CrossRef]

40. Borri, E.; Tafone, A.; Romagnoli, A.; Comodi, G. A preliminary study on the optimal configuration and operating range of a "microgrid scale" air liquefaction plant for Liquid Air Energy Storage. Energy Convers. Manag. 2017, 143, 275-285. [CrossRef]

41. Tafone, A.; Borri, E.; Comodi, G.; van den Broek, M.; Romagnoli, A. Liquid Air Energy Storage performance enhancement by means of Organic Rankine Cycle and Absorption Chiller. Appl. Energy 2018, 228, 1810-1821. [CrossRef]

42. Antonelli, M.; Desideri, U.; Giglioli, R.; Paganucci, F.; Pasini, G. Liquid air energy storage: A potential low emissions and efficient storage system. Energy Procedia 2016, 88, 693-697. [CrossRef]

43. Antonelli, M.; Barsali, S.; Desideri, U.; Giglioli, R.; Paganucci, F.; Pasini, G. Liquid air energy storage: Potential and challenges of hybrid power plants. Appl. Energy 2017, 194, 522-529. [CrossRef]

44. Barsali, S.; Ciambellotti, A.; Giglioli, R.; Paganucci, F.; Pasini, G. Hybrid power plant for energy storage and peak shaving by liquefied oxygen and natural gas. Appl. Energy 2018, 228, 33-41. [CrossRef]

45. Negro, D.; Brown, T.; Foster, A.; Damas, A.; Tovar Ramos, J.E.; Evans, J. Modelling of liquid air energy storage applied to refrigerated cold stores. In Proceedings of the 5th IIR Conference on Sustainability and the Cold Chain (ICCC 2018), Beijing, China, 6-8 April 2018; IIR: Paris, France, 2018.

46. Krawczyk, P.; Szabłowski, Ł.; Karellas, S.; Kakaras, E.; Badyda, K. Comparative thermodynamic analysis of compressed air and liquid air energy storage systems. Energy 2018, 142, 46-54. [CrossRef]

47. Li, Y.; Wang, X.; Li, D.; Ding, Y. A trigeneration system based on compressed air and thermal energy storage. Appl. Energy 2012, 99, 316-323. [CrossRef]

48. Lee, I.; You, F. Systems design and analysis of liquid air energy storage from liquefied natural gas cold energy. Appl. Energy 2019, 242, 168-180. [CrossRef]

49. Guizzi, G.L.; Manno, M.; Tolomei, L.M.; Vitali, R.M. Thermodynamic analysis of a liquid air energy storage system. Energy 2015, 93, 1639-1647. [CrossRef]

50. Xue, X.D.; Wang, S.X.; Zhang, X.L.; Cui, C.; Chen, L.B.; Zhou, Y.; Wang, J.J. Thermodynamic analysis of a novel liquid air energy storage system. Phys. Procedia 2015, 67, 733-738. [CrossRef]

51. Xie, C.; Hong, Y.; Ding, Y.; Li, Y.; Radcliffe, J. An economic feasibility assessment of decoupled energy storage in the UK: With liquid air energy storage as a case study. Appl. Energy 2018, 225, 244-257. [CrossRef] 
52. Hamdy, S.; Morosuk, T.; Tsatsaronis, G. Cryogenics-based energy storage: Evaluation of cold exergy recovery cycles. Energy 2017, 138, 1069-1080. [CrossRef]

53. Hamdy, S.; Morosuk, T.; Tsatsaronis, G. Exergetic and economic assessment of integrated cryogenic energy storage systems. Cryogenics (Guildf) 2019, 99, 39-50. [CrossRef]

54. Peng, X.; She, X.; Cong, L.; Zhang, T.; Li, C.; Li, Y.; Wang, L.; Tong, L.; Ding, Y. Thermodynamic study on the effect of cold and heat recovery on performance of liquid air energy storage. Appl. Energy 2018, 221, 86-99. [CrossRef]

55. Zhang, T.; Chen, L.; Zhang, X.; Mei, S.; Xue, X.; Zhou, Y. Thermodynamic analysis of a novel hybrid liquid air energy storage system based on the utilization of LNG cold energy. Energy 2018, 155, 641-650. [CrossRef]

56. Hüttermann, L.; Span, R. Influence of the heat capacity of the storage material on the efficiency of thermal regenerators in liquid air energy storage systems. Energy 2019, 174, 236-245. [CrossRef]

57. Sciacovelli, A.; Vecchi, A.; Ding, Y. Liquid air energy storage (LAES) with packed bed cold thermal storage-From component to system level performance through dynamic modelling. Appl. Energy 2017, 190, 84-98. [CrossRef]

(C) 2020 by the authors. Licensee MDPI, Basel, Switzerland. This article is an open access article distributed under the terms and conditions of the Creative Commons Attribution (CC BY) license (http://creativecommons.org/licenses/by/4.0/). 